Annals of Pure and Applied Mathematics

Vol. 16, No. 1, 2018, 235-239

ISSN: 2279-087X (P), 2279-0888(online)

Published on 20 January 2018

www.researchmathsci.org

DOI: http://dx.doi.org/10.22457/apam.v16n1a25

Annals of

Pure and Applied

Mathematics

\title{
Normal Exponential Exogenous Model and its Application
}

\author{
Shameena H. Khan ${ }^{1}$ and Mary Louis. $L^{2}$ \\ Department of Mathematics, Avinashilingam University \\ Tamil Nadu, India. ${ }^{1}$ E-mail: shaminakhan@yahoo.com \\ ${ }^{2}$ E-mail: marylouis69@ gmail.com \\ ${ }^{1}$ Corresponding author
}

Received 5 January 2017; accepted 18 January 2017

\begin{abstract}
The purpose of the study was to determine the inefficiency level of the firms due to the effect of exogenous factors. This paper extends the work by assuming normal distribution to random error $v$ and exponential for inefficiency error term $u$.Maximum likelihood estimation method was used for the parameter estimation. 183 maize respondents were selected through random sampling. Agro-ecological factors, financial status of the farmers and market constraints are considered as exogenous variables for the study. Results shows that damage due to bird attack has effected the production by $64 \%$. Goodness of fit test results indicates our model is fit and hypothesis test conducted reveals that there is no correlation between most of the exogenous variables.
\end{abstract}

Keywords: Normal Exponential, Maximum likelihood estimation, Exogenous factor, Inefficiency, Goodness of fit

AMS Mathematics Subject Classification (2010): 62XX, 62F03, 62FXX

\section{Introduction}

Recent development in stochastic frontier analysis focused on the incorporation of exogenous factors like weather, strikes and damaged products etc. that effects the inefficiency other than the inputs and outputs. Rubayah et al [6] in their studies on exogenous factors effect on Insurers risk and investment management efficiency considered a two stage DEA method. Yanyan Liu [9] in his contribution proposed an $\mathrm{R}^{2}$ type measure to summarize the overall explanatory power of the exogenous factors on inefficiency. Zoghbi et al. [10] conducted a study on students exogenous character effect on the inefficiency of faculty members. Lei Wang et al. [4] considered $N\left(z_{b i t} \theta_{b}, \sigma_{u}^{2}\right)$ for $u_{i}$. Wang and Schmidt [8] proposed one step model based on the scaling property in which $u$ equals a function of $z$ times one sided error $u^{*}$. Model for the inefficiency effects in stochastic production function was first proposed by Kumbhakar et al. [2] assuming one sided error component representing technical inefficiency with truncated normal distribution with mean as a linear function of exogenous factors with unknown coefficients and unknown variance. The model proposed by Reifschneider and Stevenson 


\section{Shameena H. Khan and Mary Louis. L}

[5] for the estimation of inefficiency incorporated with the effect of exogenous factors on the production process assumed to have half normal. Battese and Coelli [1] proposed a model for inefficiency on a panel data as $U_{i t}=Z_{i t} \delta+W_{i t}$, here $Z_{i t} \delta$ is associated with the exogenous variables. Exogenous variables with negative coefficient in the regression indicates that firms with larger values of the variables tends to have lower level of inefficiencies (Subhal C Kumbhakar et al. [7]). stochastic frontier models should be used to explore the effect of external variables influence on the farmer's performance (Kumbhakar and Lovell, [3]). In this paper we have considered exponential distribution for the error term associated with exogenous factor. Our main objective is to apply the derived model and hence to identify the exogenous factor effect on efficiency of the firm. Using structural equation modelling Analysis was carried out on 183 maize farmers from the southern region of India. Multistage stratified sampling technique was adopted for sample collection. Hypothesis test is carried out.

\section{Normal-exponential exogenous model}

In this formulation,

The distributional assumptions are:

1) $v_{i} \sim$ iid $N\left(0, \sigma_{v}^{2}\right)$

2) $u_{i} \sim$ iid exponential.

3) $v_{i}$ and $u_{i}$ are distributed independently of each other and of the regressors

Probability density function of $\mathrm{v}$ is given by,

$$
f(v)=\frac{1}{\sqrt{2 \pi} \sigma_{v}} e^{\frac{-v^{2}}{2 \sigma_{v}^{2}}}
$$

Probability density function of $\mathrm{u}$ is given by,

$$
f(u)=\frac{1}{\sigma_{u}+h(z, \gamma)} e^{\frac{-u}{\sigma_{u}+h(z, \gamma)}}
$$

Joint density function of $u$ and $v$ is given by

$$
f\left(\begin{array}{ll}
u & v
\end{array}\right)=\frac{1}{\sqrt{2 \pi} \sigma_{v}\left(\sigma_{u}+h(z, \gamma)\right)} e^{-\frac{v^{2}}{2 \sigma_{v}^{2}}-\frac{u}{\sigma_{u}+h(z, \gamma)}}
$$

The joint density function of $\mathrm{u}$ and $\varepsilon$ is obtained by taking the transformation $\varepsilon=v-u$

$$
f(u, \varepsilon)=\frac{1}{\sqrt{2 \pi} \sigma_{v}\left(\sigma_{u}+h(z, \gamma)\right)} e^{\frac{-(\varepsilon+u)^{2}}{2 \sigma_{v}^{2}}-\frac{u}{\sigma_{u}+h(z, \gamma)}}
$$

On further simplification,

$$
f(u, \mathcal{E})=\frac{1}{\sqrt{2 \pi} \sigma_{v}\left(\sigma_{u}+h(z, \gamma)\right)} e^{\frac{-1}{2}\left\{\frac{u}{\sigma_{v}}+\left(\frac{\varepsilon}{\sigma_{v}}+\frac{\sigma_{v}}{\sigma_{u}+h(z, \gamma)}\right)\right\}^{2}} e^{\frac{1}{2}\left(\frac{2 \varepsilon}{\sigma_{u}+h(z, \gamma)}+\frac{\sigma_{v}^{2}}{\left(\sigma_{u}+h(z, \gamma)\right)^{2}}\right)}
$$

The marginal density function of $\varepsilon$ is obtained by integrating $f(u, \varepsilon)$ with respect to u.

$$
f(\varepsilon)=\int_{0}^{\infty} f(u, \varepsilon) d u
$$

Hence, 
Normal Exponential Exogenous Model and its Application

$$
f(\varepsilon)=\frac{1}{\left(\sigma_{u}+h(z, \gamma)\right)} e^{\frac{1}{2}\left(\frac{2 \varepsilon}{\sigma_{u}+h(z, \gamma)}+\frac{\sigma_{v}^{2}}{\left(\sigma_{u}+h(z, \gamma)\right)^{2}}\right)}\left(1-\Phi\left(\frac{\varepsilon}{\sigma_{v}}+\frac{\sigma_{v}}{\sigma_{u}+h(z, \gamma)}\right)\right)
$$

The likelihood function of the sample is the product of the density function of the individual observations, which is given as,

$$
\operatorname{In} L=-\operatorname{In}\left(\sigma_{u}+h(z, \gamma)\right)+\frac{1}{2} \sum_{i=1}^{k} \frac{\sigma_{v}^{2}}{\left(\sigma_{u}+h(z, \gamma)\right)^{2}}+\sum_{i=1}^{k} \frac{\varepsilon}{\sigma_{u}+h(z, \gamma)}+\sum_{i=1}^{k} \operatorname{In}\left(1-\Phi\left(\frac{\varepsilon}{\sigma_{v}}+\frac{\sigma_{v}}{\sigma_{u}+h(z, \gamma)}\right)\right)
$$

Point estimation of Normal-Exponential Stochastic Frontier Model for exogenous factor influence:

As $f(u / \varepsilon)$ is distributed as $N^{1}\left(\mu_{*} \sigma_{*}^{2}\right)$, the mean of this distribution serves as a point estimator of $u_{i}$ which is given by

$$
\begin{aligned}
& E(u / \varepsilon)=\int_{0}^{\infty} u f(u / \varepsilon) d u \\
& E(u / \varepsilon)=\int_{0}^{\infty} u \frac{1}{\sigma_{v} \sqrt{2 \pi}}\left(1-\Phi\left(\frac{\hat{\mu}}{\sigma_{v}}\right)\right)^{-1} e^{\frac{-1}{2}\left(\frac{u+\hat{u}}{\sigma_{v}}\right)^{2}} d u
\end{aligned}
$$

Simplifying further (8) yields,

$$
E(u / \varepsilon)=\frac{\phi\left(\frac{\hat{\mu}}{\sigma_{v}}\right) \sigma_{v}}{1-\Phi\left(\frac{\hat{\mu}}{\sigma_{v}}\right)}-\hat{\mu}
$$

The effect of each environmental variable on technical inefficiency can be calculated

from $\frac{\partial E\left(u_{i} / \varepsilon_{i}\right)}{\partial z_{i}}$ after the inefficiency has been estimated.

\section{Results and discussion}

NEEM was applied to a cross sectional data of 183 maize farmers in the southern region of India. Through a structured questionnaire farmers were interviewed. Five likert skills like Strongly agree-1, Agree-2, Neutral-3, Disagree-4, Strongly disagree-5 was provided for the responses on exogenous factors. The indicators used to analyse the influencing factors from the exogenous perspective on the performance difference of each firm is based on the crop and study area. Peripheral circles show the exogenous factors which are the influencing factors on the technical efficiency of farmers. Technical efficiency is comprised of inputs and outputs viz; seed(kg), labour(no), machinery(hr), Fertilizer(kg), plant protection chemicals( $\mathrm{kg}$ ), irrigation(no) and Yield(quintal).

Parameter estimation was carried out using structural equation modelling in STATA with technical efficiency as dependent variable and climate, marketing, financial conditions of the farmer and damage due to bird attack as exogenous variables.

The inefficiency model for the influencing factors on $T e_{i}$ is given by, $U_{i}=\mu_{0}+\mu_{1} a_{1 i}+\mu_{2} a_{2 i}+\mu_{3} a_{3 i}+\mu_{4} a_{4 i}$ where $a_{1 i}$ is the climate, $a_{2 i}$ market status, $a_{3 i}$ financial condition of farmer and $a_{4 i}$ damage to the crop. 
Shameena H. Khan and Mary Louis. L

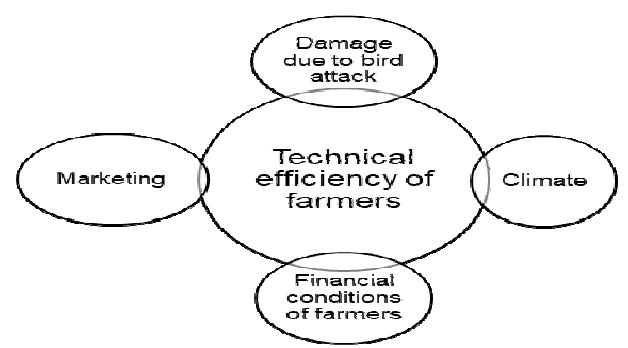

Figure 1: Maize growing farmer's performance assessment influencing factors.

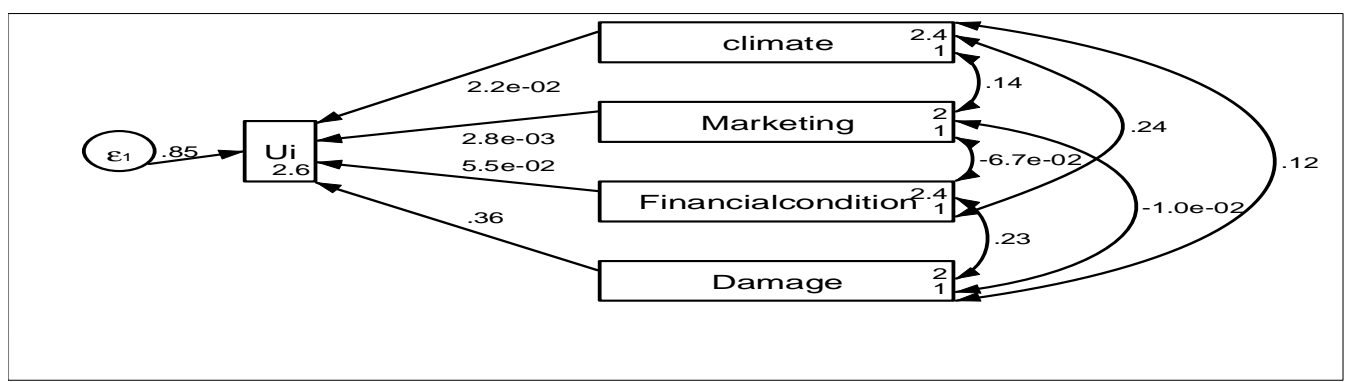

Figure 2: Model for the Incorporation of exogenous factors on inefficiency.

\begin{tabular}{|c|c|c|c|c|c|}
\hline \multirow{2}{*}{\multicolumn{4}{|c|}{$\begin{array}{l}\text { Table 1. Maximum likelihood estimation and } \\
\text { Hypothesis results }\end{array}$}} & \multicolumn{2}{|l|}{ Table 2. Goodness of fit } \\
\hline & & & & Fit Statistic & Value \\
\hline \multirow[b]{2}{*}{ Standardized } & \multirow{2}{*}{$\begin{array}{l}\text { Std. } \\
\text { Err. }\end{array}$} & \multirow[b]{2}{*}{$\mathrm{z}$} & \multirow[b]{2}{*}{$\mathrm{P}>\mathrm{Z}$} & \multicolumn{2}{|l|}{ Likeli Hood ratio } \\
\hline & & & & \multirow{2}{*}{$\begin{array}{lc}\text { chi2_ms }(0) \\
\text { chi2 bs(4) }\end{array}$} & 0 \\
\hline \multicolumn{4}{|l|}{ Structural Ui <- } & & \multirow{2}{*}{$\begin{array}{l}29.145 \\
0\end{array}$} \\
\hline \multicolumn{4}{|l|}{ Climate } & p>chi2 & \\
\hline \multirow{3}{*}{$\begin{array}{l}\text { Marketing } \\
\text { Financial condition } \\
\text { Damage }\end{array}$} & 0.069 & 0.04 & 0.968 & \multicolumn{2}{|l|}{ Population error } \\
\hline & 0.0722 & 0.77 & 0.442 & \multirow{3}{*}{$\begin{array}{lr}\text { RMSEA(Root } & \text { mean } \\
\text { squared error } & \text { of } \\
\text { approximation) } & \end{array}$} & \multirow[b]{3}{*}{0} \\
\hline & 0.066 & 5.5 & 0 & & \\
\hline cons & 0.34 & 7.76 & 1.9 & & \\
\hline \multicolumn{4}{|l|}{ Correlation } & RMSE $<=0.05$ & \\
\hline \multicolumn{4}{|l|}{ Climate> } & \multicolumn{2}{|l|}{ Base line comparison } \\
\hline Marketing & 0.0724 & 1.96 & 0.05 & \multicolumn{2}{|l|}{ CFI(Comparative fit index) } \\
\hline Financial condition & 0.069 & 3.38 & 0.001 & TLI(Tucker-Lewis index) & 0.995 \\
\hline Damage & 0.073 & 1.71 & 0.087 & & \\
\hline \multicolumn{4}{|l|}{ Marketing> } & & \\
\hline Financial condition & 0.073 & -0.92 & 0.36 & & \\
\hline Damage & 0.074 & -0.14 & 0.887 & & \\
\hline \multicolumn{4}{|l|}{ Financial condition> } & & \\
\hline Damage & 0.069 & 3.36 & 0.001 & & \\
\hline Variance e. Ui & 0.048 & & & & \\
\hline
\end{tabular}

Regression coefficient of climate, marketing, financial condition and damage as per figure is estimated as $0.022,0.0028,0.055,0.36$ and constant is 2.6. Hence the estimated exogenous inefficiency model is, $U_{i}=2.6+0.022 a_{1 i}+0.003 a_{2 i}+0.055 a_{3 i}+0.36 a_{4 i}$ 
Normal Exponential Exogenous Model and its Application

Mean and variance of climate is 2.4 and 1 ; for marketing it is 2 and 1. Financial condition of farmers has the mean and variance as 2.4 and land damages of the crop due to bird attack is recorded as 2 and 1 . Variance of technical error is given as 0.85 . Using Table 1 significance level of exogenous variable on efficiency has been estimated. Results shows that exogenous factor damage is significant to the efficiency of production, where as other factors have significance level above 5\% hence it has not affected the production.

\section{Conclusion}

In this paper, we have derived a model for the estimation of exogenous factor influence on efficiency of the firms. In this study null hypothesis is accepted and goodness of fit test reveals that our model is fit. Results shows that $64 \%$ of the production is effected due to bird attack in the study area. More training programme can be given in relation to the above findings in order to use latest technologies to save the crop from birds.

Acknowledgement. We are very grateful to the referees for their valuable suggestions to improve this paper in its present form.

\section{REFERENCES}

1. G.E.Battese and T.J.Coelli, A model for technical inefficiency effects in a stochastic frontier production function for panel data, Empirical Economics, 20 (1995) 325-32.

2. S.C.Kumbhakar, S.Ghosh and J.T.McGuckin, A generalized production frontier approach for estimating determinants of inefficiency in US dairy farms, Journal of Business and Economic Statistics, 9 (1991) 279-86.

3. S.C.Kumbhakar and C.A.K.Lovell, Stochastic Frontier Analysis. Cambridge University Press, (2000).

4. L.Wang, R.Long and H.Chen, Study of urban energy performance assessment and its influencing factors based on improved stochastic frontier analysis: a case study of provincial capitals in China, Sustainability, 9 (2017).

5. D.Reifschneider and R.Stevenson, Systematic departures from the frontier: A framework for the analysis of firm inefficiency, International Economic Review, 32(3) (1991) 715-23.

6. R.Yakob, Z.Yusop, A.Radam and N.Ismail, Two-stage dea method in identifying the exogenous factors of insurers' risk and investment management efficiency, Sains Malaysiana, 43(9) (2014) 1439-1450.

7. S.C.Kumbhakar, H.-J.Wang and A.P.Horncastle, A Practitioner's guide to stochastic frontier analysis using Stata, Cambridge University Press, (2015).

8. Wang and Schmidt, One-step and two-step estimation of the effects of exogenous variables on technical efficiency levels, Journal of Productivity Analysis, 18 (2002) 129-144.

9. Y.Liu, Model Selection in Stochastic Frontier Analysis: Maize Production in Kenya, Selected Paper prepared for presentation at the American Agricultural Economics Association Annual Meeting, (2006).

10. A.C.Zoghbi, F.Rocha and E.Mattos, Education production efficiency: Evidence from Brazilian universities, Economic Modelling, 31 (2013) 94-103. 